\title{
Patient safety culture in Norwegian home health nursing: a cross-sectional study of healthcare provider's perceptions of the teamwork and safety climates
}

Rose Mari Olsen ${ }^{1,3^{*}}$ and Jorunn Bjerkan ${ }^{2}$

\begin{abstract}
Background: The threefold aim of this study was to (1) describe attitudes to patient safety among healthcare providers in home health nursing (HHN), (2) investigate differences in attitudes due to age, education level, years of healthcare work experience, and years at current workplace, and (3) compare attitudes of these HHN healthcare providers with available benchmark data from other healthcare settings.

Methods: One hundred sixty HHN healthcare providers in Mid-Norway answered a survey covering the teamwork climate and safety climate in the Safety Attitudes Questionnaire (SAQ). Data were analyzed by descriptive statistics, $t$ test, and ANOVA.

Results: The overall mean score was 79.1 for teamwork climate and 72.3 for safety climate. The proportion of positive responses (i.e., scale scores $\geq 75$ ) was $73 \%$ on teamwork climate and $53 \%$ on safety climate. For teamwork and safety climates, employees with the longest employment at the current workplace had significantly higher mean scores than those with shorter employment. No significant differences were found in mean scores for age, education level, and length of experience in healthcare. Compared to benchmark data from other studies, the mean HHN scores for both safety and teamwork climates were higher than in the vast majority of other healthcare settings and significant differences were found for both dimensions.

Conclusion: HHN has higher scores for both safety climate and teamwork climate compared to the vast majority of other healthcare settings, but there is room for improvement in the patient safety culture within the Norwegian HHN. Further research on patient safety culture in HHN is needed.
\end{abstract}

Keywords: Safety Attitudes Questionnaire (SAQ), Safety climate, Teamwork climate, Norway, Home health nursing, Primary care

\section{Background}

In this study, we investigate attitudes towards patient safety in the context of home health nursing (HHN) in Norway. Patient safety, defined as "... the reduction of risk of unnecessary harm associated with healthcare to an acceptable minimum" [1], has been a topic of considerable public and professional interest over the last two

\footnotetext{
* Correspondence: rose.m.olsen@nord.no

${ }^{1}$ Centre for Care Research Mid-Norway, Nord University, Namsos, Norway

${ }^{3}$ Centre for Care Research/Faculty of Nursing and Health Science, PB 474,

7801 Namsos, Norway

Full list of author information is available at the end of the article
}

decades [2-5]. Although patient safety is a complex issue relevant to any aspect of nursing and medical care, we find a predominance of articles relating to hospital care. Far less research is available on patient safety issues in primary care [5-8]. This is worrisome, as most patients receive their healthcare in primary settings-both in Norway and other European countries [9].

A systematic review of international studies states that adverse events occur in 1-2 per 100 patient consultations in primary care [10]. In Norway, only hospitals are obliged to report adverse event; thus, we have no exact overview of primary care incidents. However, cases received 
by The Norwegian System of Compensation to Patients [11] and The Health \& Social Services ombudsmen [12] indicate that adverse events are also present in primary care. A long-term government safety program "In safe hands 24-7" that evolved from a 2011 to 2014 national campaign [13] has contributed to extensive efforts to systematically work on patient safety in recent years. Some target areas also address/involve primary care, e.g., systematic interdisciplinary drug reviews with reconciliation of drug lists, but most areas have been directed towards hospital care.

In regard to primary care, patient safety issues have mainly been addressed in nursing homes [8]. The growth of the elderly population and an increasing proportion of patients being cared for in their homes warrant a focus on patient safety in HHN. In Norway, older people (aged 67 years or above) account for almost 60\% of the 149,551 patients receiving HHN each year [14]. This patient group is especially vulnerable to adverse events because they often have complex care needs caused by multimorbidity, polypharmacy, and multiple functional limitations [6, 15-18]. In addition, the risks to older patients in their own homes are rather different from those in institutions, e.g., different environment, roles, and failure to monitor over long periods.

An important first step in preventing adverse events occurring in older people receiving $\mathrm{HHN}$ is to gain knowledge about patient safety culture in the services. Patient safety culture can be defined as an "integrated pattern of individual and organisational behaviour, based upon shared beliefs and values that continuously seeks to minimise patient harm, which may result from the processes of care delivery" [19]. A strong patient safety culture seems to correlate with a positive effect on the quality and safety level of patient treatment [20]. We also find associations between patient safety culture and adverse events [21, 22], e.g., decreased urinary tract infections and medication errors [23], fewer fall incidents, and less use of restraints [24]. Measuring patient safety culture is an important tool for patient safety improvements $[25,26]$ and should be monitored as close to the patient context as possible [27]. Such mapping might provide information for managers and involved professionals to take action to increase patient safety [28-30].

There is a lack of studies investigating patient safety culture in HHN. Gallego et al. [31], which is the only study we are aware of investigating this setting, reported that cultural differences manifest between different service types. In their study, HHN staff tended to report more positive attitudes towards patient safety issues than staff members from several other healthcare settings [31]. In comparison, studies have found safety culture in nursing homes to be poorer [32, 33] but also better [34] than in other healthcare services.
Expanding knowledge on HHN staff and their attitudes towards patient safety may form the basis for patient safety interventions and further research in a HHN care context. The threefold aim of this study was to (1) describe attitudes to patient safety among healthcare providers in HHN, (2) investigate differences in attitudes due to age, education level, years of work experience in healthcare, and years at current workplace, and (3) compare attitudes of these HHN healthcare providers to available benchmark data from other healthcare settings.

\section{Methods}

The study was of cross-sectional design and carried out during December 2015 to February 2016.

\section{Sample and setting}

The data for the present study were collected in HHN in six municipalities in Mid-Norway. These municipalities are part of a national panel of "care-municipalities," which were selected to be representative in terms of geographic location and size. The panel was established by the Centre for Care Research (http://www.omsorgsforskning.no/ english). The home care services in Norway include both nursing care (e.g., assistance with personal hygiene, meals, wound care, and medication) and/or practical help (e.g., in-home cleaning and laundry services). This study only included healthcare providers delivering nursing care.

\section{Questionnaire}

Patient safety culture is a complex phenomenon typically assessed through quantitative questionnaires based upon operationalized dimensions [35]. Among these, the Safety Attitudes Questionnaire (SAQ) is one of the most widely used instruments [36]. The original SAQ was developed to measure patient safety culture in critical care units and includes 60 items concerning six factors: teamwork climate, safety climate, job satisfaction, perception of management, working conditions, and stress recognition [37].

To measure patient safety attitudes in $\mathrm{HHN}$, we used a survey based on the Norwegian SAQ, Generic version, Short Form 2006 [38]. However, we only used the teamwork climate (6 items) and safety climate (7 items) scales in this study. The reason for this was that we wanted to reduce the time needed to complete the survey and thus improving response rates. Answers were given on a 5-point Likert scale: 1 = disagree strongly, 2 = disagree slightly, $3=$ neutral, $4=$ agree slightly, and $5=$ agree strongly. "Not applicable" was included as a response category for all items, and this was set as "missing" in the analyses. Two of the items were negatively worded (see Table 1, items no. 2 and 11), and they were reversed so that higher scores in the data always indicate a more positive perception of the patient safety climate. The 
Table 1 Mean score for the 13 items in teamwork climate and safety climate in SAQ

\begin{tabular}{|c|c|c|c|c|c|}
\hline Dimensions & Items & Missing $^{\mathrm{b}}, n$ & Mean & (SD) & Positive answers ${ }^{\mathrm{c}}, \%$ \\
\hline \multirow{7}{*}{$\begin{array}{l}\text { Teamwork } \\
\text { climate }\end{array}$} & Total & 0 & 79.1 & $(17.4)$ & 73.3 \\
\hline & 1. My input is well received in this clinical area & 0 & 77.8 & (24.6) & 77.6 \\
\hline & 2. In this clinical area, it is difficult to speak up if I perceive a problem with patient care ${ }^{a}$ & 0 & 75.3 & $(30.7)$ & 78.1 \\
\hline & $\begin{array}{l}\text { 3. Disagreements in this clinical area are resolved appropriately (i.e. not who is right, but } \\
\text { what is best for the patient) }\end{array}$ & 0 & 74.4 & $(29.8)$ & 72.5 \\
\hline & 4. I have the support I need from other personnel to care for patients & 0 & 84.1 & $(23.7)$ & 86.9 \\
\hline & $\begin{array}{l}\text { 5. It is easy for personnel here to ask questions when there is something that they do } \\
\text { not understand }\end{array}$ & 1 & 87.0 & $(23.3)$ & 88.7 \\
\hline & 6. The personnel here work together as a well-coordinated team & 0 & 76.0 & $(26.4)$ & 78.7 \\
\hline \multirow{8}{*}{$\begin{array}{l}\text { Safety } \\
\text { climate }\end{array}$} & Total & 5 & 72.3 & $(17.8)$ & 52.9 \\
\hline & 7. I would feel safe being treated here as a patient & 5 & 78.9 & $(25.0)$ & 78.7 \\
\hline & 8. Medical errors are handled appropriately in this clinical area & 6 & 77.6 & $(26.7)$ & 79.3 \\
\hline & $\begin{array}{l}\text { 9. I know the proper channels to direct questions regarding patient safety in this } \\
\text { clinical area }\end{array}$ & 5 & 77.7 & $(25.4)$ & 77.4 \\
\hline & 10. I receive appropriate feedback about my performance & 6 & 66.4 & (26.6) & 60.7 \\
\hline & 11. In this clinical area, it is difficult to discuss errors ${ }^{\text {a }}$ & 5 & 62.9 & $(30.2)$ & 57.5 \\
\hline & $\begin{array}{l}\text { 12. I am encouraged by my colleagues to report any patient safety concerns I may } \\
\text { have }\end{array}$ & 5 & 73.7 & $(26.2)$ & 71.0 \\
\hline & 13. The culture in this clinical area makes it easy to learn from the errors of others & 8 & 68.6 & $(26.1)$ & 61.8 \\
\hline
\end{tabular}

${ }^{a}$ The items 2 and 11 were reversed so that higher scores in the data always indicate a more positive perception of the patient safety climate

"The response category "Not applicable" was set as "missing" in the analyses

'Positive answers was defined as score $\geq 75$

scales were rescaled to a 100 -point scale where $1=0$, $2=25,3=50,4=75$, and $5=100$. Consistent with Sexton et al. [37], scores $\geq 75$ were considered as an indication of a positive perception of the patient safety climate.

As the SAQ, Generic version, Short Form 2006 was developed for use in inpatient care; two of the items were modified slightly. The item "Nurse input is well received in this clinical area" was modified to "My input is well received in this clinical area"; the item "The physicians and nurses here work together as a wellcoordinated team" was modified to "The personnel here work together as a well-coordinated team".

The survey also incorporated demographic items, including age, gender, education, years of work experience in healthcare, and years at current workplace.

\section{Data collection}

Healthcare managers of the home care services provided the email addresses of all employees having direct patient contact in their HHN work. The survey was electronically distributed to the employees via the software program Enalyzer (www.enalyzer.com/no), and the respondents answered anonymously. Enalyzer sent reminders automatically to those who had not answered.

\section{Statistical analysis}

The data is described using frequencies, percentages, means, standard deviation (SD), median, range (minimum and maximum), and missing values. The teamwork and safety climate scales were used as continuous variables with a range from 0 to 100 [37]. The score was calculated by subtracting 1 from the mean, and the result was multiplied by 25 [38]. Scales were only calculated for respondents that answered all of the items in the scales used to calculate the scores. Reliability of the teamwork and safety climate scales was investigated using Cronbach's alpha $(\alpha)$, with 0.70 as the minimum criterion.

An independent sample $t$ test was used to investigate differences in mean score for the two SAQ scales between the subgroups: education level (lower degree versus bachelor degree), years at current workplace, $(<4$ versus $\leq 4$ years), and years of work experience in healthcare ( $\leq 15$ versus $>15$ years). ANOVA was used to investigate differences in mean score between age groups $(\leq 29$, $30-39,40-49,50-59$, and $\geq 60$ years).

A summary independent sample $t$ test was performed in order to test differences in mean scores between our sample and benchmark data from other settings, including Norwegian out-of-hours casualty clinics and general practitioner (GP) practices [39], Dutch nursing/residential homes [34], acute care hospitals in seven European countries [40], Swedish surgical inpatient units [41], and Norwegian nursing homes [32]. We considered these studies appropriate for comparison to our $\mathrm{HHN}$ data because they included SAQ mean scores for frontline nurses (i.e., registered nurse, nurse assistant, health worker, 
and licensed practical nurse), either as a subgroup score or the study solely included nurses. The benchmark data from Buljac-Samardzic et al. [34] also included paramedical staff and doctors (i.e., mean score for nurses was not presented separately), but these professionals accounted for only $4.7 \%$ of the total sample.

In Olsson et al. [41], the mean SAQ value was calculated and presented in its true interval, i.e., 1.00-5.00. In order to use their data as a benchmark in our study, we calculated their presented means into the interval 1-100 (by subtracting 1 from the mean and multiplying by 25, [38]. Statistical analyses were performed using SPSS (Version 23.0).

\section{Results}

\section{Sample demographics}

In total, 160 (28\%) out of 580 employees from 16 different HHN units in six municipalities responded to the survey. Of those who did not participate, 36 refused and 384 did not respond to the request. Response rate per unit $(N=$ 16) varied between 20 and 66\%. The sample included 156 women and 4 men. Half of those sampled were educated to the bachelor degree level (77 registered nurses, 3 social educators), and the other half were educated to a lower level (77 nurse assistants, 2 nursing students, 1 unlicensed assistive person). Sixty-three percent were aged 40 years or older. The mean length of healthcare work experience was 17 years (median 16, range $0-45$ ), and $72 \%$ had been employed at their current workplace for at least 4 years.

\section{Mean scores and proportion of positive responses regarding teamwork and safety climate}

Responses to the 13 items for teamwork and safety climate are shown in Table 1, including scale means, SD, and the proportion of positive responses ( $\geq 75$ out of 100). The highest mean on a single item was related to teamwork climate "It is easy for personnel here to ask questions when there is something that they do not understand" (87.0), while the lowest mean score was related to safety climate "In this clinical area, it is difficult to discuss errors" (62.9). These two items were also given the highest (88.7\%) and lowest (57.5\%) proportions of positive scores, respectively. The Cronbach's alpha values for the scales were satisfactory ( $\alpha=0.72$ on teamwork climate, $\alpha=0.78$ on safety climate).

The overall mean score for teamwork climate was 79.1 $(\mathrm{SD}=17.4)$ and $72.3(\mathrm{SD}=17.8)$ for safety climate (Table 1$)$. The maximum score on both scales was 100 , whereas the minimum score was 17 for teamwork climate and 25 for safety climate. The proportion of positive responses was $73.3 \%$ for teamwork climate and $52.9 \%$ for safety climate.

\section{Differences in safety attitudes due to age, educational level, and work experience}

Table 2 gives an overview of mean scores for teamwork and safety climate by age, education level, years of healthcare work experience, and years at current workplace. For both dimensions, we found that employees with the longest employment at their current workplace had significantly higher scores than those with a shorter employment period. The mean score for teamwork climate was 80.9 in the group that had worked $\geq 4$ years at the workplace, while the group with a shorter employment period scored $74.3(p=0.03)$. Correspondingly, scores for the safety climate were 74.3 and $66.8(p=0.02)$. No significant differences were found in mean scores for education level and years of healthcare work experience.

\section{Teamwork and safety climate in home health nursing compared to benchmark data}

In Table 3, the mean scores for teamwork and safety climate in HHN are compared to benchmark data from six other settings: Norwegian out-of-hours casualty clinics and GP practices [39], Dutch nursing/residential homes [34], acute hospitals in seven European countries [40], Swedish inpatient surgery units [41], and Norwegian nursing homes [32]. For teamwork climate, HHN scores were significantly higher than in three of the benchmark settings: nursing homes and residential homes in the Netherlands, acute hospitals in Europe, and nursing homes in Norway. The HHN scores were also significantly higher than in two of the benchmark settings for safety climate: nursing homes and residential homes in the Netherlands, and acute care hospitals in Europe. The largest differences were for teamwork climate, where HHN scored 79.1, and European acute hospitals, which scored $65.0(p<0.001) \cdot$ th $=$ tlb $=$

\section{Discussion}

While teamwork climate was reported as positive by almost three quarters of the HHN employees, only half of them perceived the safety climate as positive. The overall mean score was, however, high for both dimensions and, in sum, this shows great variation in the employees responses. For both teamwork climate and safety climate, healthcare providers with the longest employment at their current workplace had significantly higher mean scores than those with shorter employment. No significant differences were found in mean scores for age, education level, and length of experience in healthcare. Compared to benchmark data from other studies, the HHN mean scores for both safety climate and teamwork climate were higher than in the vast majority of other healthcare settings and statistically significant differences were found for both dimensions. 
Table 2 Differences in mean scores on teamwork and safety climate due to age, educational level, work experience in health care, and years at current workplace

\begin{tabular}{|c|c|c|c|c|c|}
\hline \multicolumn{2}{|l|}{ Dimensions SAQ } & \multirow{2}{*}{$\begin{array}{l}\text { Number } \\
160\end{array}$} & \multirow{2}{*}{$\begin{array}{l}\text { Mean } \\
79.1\end{array}$} & \multirow{2}{*}{$\frac{(S D)}{(17.4)}$} & \multirow[t]{2}{*}{$p$ value } \\
\hline Teamwork climate & Total & & & & \\
\hline & Education & & & & 0.92 \\
\hline & Bachelor degree & 80 & 78.9 & $(18.0)$ & \\
\hline & Lower degree & 80 & 79.2 & $(16.9)$ & \\
\hline & Age (years) & & & & 0.45 \\
\hline & $\leq 29$ & 22 & 81.7 & $(13.1)$ & \\
\hline & $30-39$ & 37 & 80.7 & $(18.9)$ & \\
\hline & $40-49$ & 52 & 77.3 & $(18.4)$ & \\
\hline & $50-59$ & 34 & 76 & $(17.2)$ & \\
\hline & $\geq 60$ & 15 & 84.2 & $(15.9)$ & \\
\hline & Years employed at current workplace & & & & 0.03 \\
\hline & $<4$ & 43 & 74.3 & $(19.1)$ & \\
\hline & $\geq 4$ & 117 & 80.9 & $(16.5)$ & \\
\hline & Years of experience in health care & & & & 0.89 \\
\hline & $\leq 15$ & 78 & 78.9 & $(17.5)$ & \\
\hline & $>15$ & 82 & 79.3 & $(17.4)$ & \\
\hline \multirow[t]{16}{*}{ Safety climate } & Total & 155 & 72.3 & $(17.8)$ & \\
\hline & Education & & & & 0.42 \\
\hline & Bachelor degree & 76 & 71.1 & $(18.0)$ & \\
\hline & Lower degree & 79 & 73.4 & $(17.7)$ & \\
\hline & Age (years) & & & & 0.22 \\
\hline & $\leq 29$ & 22 & 70.5 & $(14.5)$ & \\
\hline & $30-39$ & 35 & 76.2 & $(18.7)$ & \\
\hline & $40-49$ & 50 & 68.7 & $(19.0)$ & \\
\hline & $50-59$ & 33 & 72.0 & (16.6) & \\
\hline & $\geq 60$ & 15 & 78.3 & $(17.7)$ & \\
\hline & Years employed at current workplace & & & & 0.02 \\
\hline & $<4$ & 42 & 66.8 & $(17.2)$ & \\
\hline & $\geq 4$ & 113 & 74.3 & $(17.7)$ & \\
\hline & Years of experience in health care & & & & 0.46 \\
\hline & $\leq 15$ & 75 & 71.2 & (16.9) & \\
\hline & $>15$ & 80 & 73.3 & (18.7) & \\
\hline
\end{tabular}

Note: Significant $p$ values (level $95 \%$ ) are indicated in italics

The HHN had a higher overall mean score for teamwork climate than all of the benchmark settings, except for nurses in the Norwegian out-of-hours setting, which showed a similar score. In addition, Gallego et al. [31], who used SAQ when comparing safety attitudes of services types across the Australian health system, found that home care (i.e., Royal District Nursing Service) was among the services reporting the highest teamwork climate scores. Unfortunately, as Gallego et al. [31] did not report exact factor scores in their article, we could not compare mean scores between the studies. In our study, the fact that HHN employees scored significantly higher than healthcare providers in Dutch and Norwegian nursing/residential homes and European acute hospitals lends itself to different interpretations: one could be that working practices and conditions in the $\mathrm{HHN}$ services are rather different from those in institutional care. HHN healthcare providers mainly work alone in the patient's home, meeting their colleagues and leaders only a few times during a work shift to report and discuss their nursing interventions. They experience greater autonomy than nurses working in nursing homes [42]. They need to be flexible and skilled in being able to adapt care to the home care service delivery setting while maintaining 
Table 3 Mean scores for teamwork climate and safety climate in home health nursing compared with benchmarking data

\begin{tabular}{|c|c|c|c|c|c|c|c|c|c|c|c|c|c|}
\hline \multirow{3}{*}{$\begin{array}{l}\text { Dimensions } \\
\text { SAQ }\end{array}$} & \multirow{3}{*}{$\begin{array}{l}\text { Scores, home } \\
\text { health nursing } \\
\text { Mean (SD) }\end{array}$} & \multicolumn{12}{|c|}{ Benchmarking scores } \\
\hline & & \multicolumn{2}{|c|}{$\begin{array}{l}\text { GP practices, } \\
\text { Norway }\end{array}$} & \multicolumn{2}{|c|}{$\begin{array}{l}\text { Out-of-hours } \\
\text { casualty clinics, } \\
\text { Norway }\end{array}$} & \multicolumn{2}{|c|}{$\begin{array}{l}\text { Nursing and } \\
\text { residential homes, } \\
\text { the Netherlands }\end{array}$} & \multicolumn{2}{|c|}{$\begin{array}{l}\text { Acute hospital, } \\
\text { seven European } \\
\text { countries }\end{array}$} & \multicolumn{2}{|c|}{$\begin{array}{l}\text { Surgical hospital } \\
\text { care, Sweden }\end{array}$} & \multicolumn{2}{|c|}{$\begin{array}{l}\text { Nursing homes, } \\
\text { Norway }\end{array}$} \\
\hline & & Mean (SD) & $p$ value & Mean (SD) & $p$ value & Mean (SD) & $p$ value & Mean (SD) & $p$ value & Mean (SD) & $p$ value & Mean (SD) & $p$ value \\
\hline $\begin{array}{l}\text { Teamwork } \\
\text { climate }\end{array}$ & $79.1(17.4)$ & $75.6(16.8)$ & 0.202 & $79.3(12.4)$ & 0.921 & $70.1(13.1)$ & 0.000 & $65.0(18.8)$ & 0.000 & $77.5(12.5)$ & 0.273 & $72.5(19.4)$ & 0.001 \\
\hline $\begin{array}{l}\text { Safety } \\
\text { climate }\end{array}$ & $72.3(17.8)$ & $75.1(17.9)$ & 0.306 & $75.4(16.2)$ & 0.234 & $64.5(12.4)$ & 0.000 & $65.7(16.2)$ & 0.000 & $70.0(15.0)$ & 0.140 & $70.8(18.0)$ & 0.425 \\
\hline
\end{tabular}

Note: $p$ values correspond to difference of means between home health nursing and each of the benchmark settings. Significant $p$ values (level 99\%) are indicated in italics. ${ }^{a} \mathrm{~N}$ for home health nursing was 160 for teamwork climate and 155 for safety climate

appropriate nursing standards [43]. HHN can be viewed as a "ward without walls" [44] where beds never close regardless of external factors. Thus, staff have to work in close collaboration and organize their workloads to share clients [45]. In the present study, most healthcare providers reported it to be easy to rely on each other's help and assistance when needed (i.e., high mean score and positive responses for items 4 and 5), indicating that they also have trust in one another. Thus, the HHN meets the characteristics of a "real team," described by Katzenbach and Smith [46]. According to Katzenbach and Smith, a "real team" has high interdependence, whereas teams with low interdependence are more commonly labeled "working groups." In a real team, the members share a common purpose and approach, they have complementary skills, and they hold themselves mutually accountable for their results [46].

The HHN had a lower mean score for safety climate than teamwork climate. This is in contrast to Gallego et al. [31], who found that healthcare providers in home care scored higher for safety climate than teamwork climate. The reported difficulty of discussing errors in our study (low mean score and low positive responses for item 11) may seem to be a contradiction to the high proportion of positive responses for teamwork climate. One explanation could be a fragile trust between the employees relying on each other for help, where discussing errors may be regarded as splitting the team loyalty. Jones and Kelly [47] found that staff members who witnessed wrongdoing avoided formal whistle-blowing routes and instead raised concerns in other more informal and less explicit ways (e.g., raised their concerns verbally indirectly via the use of humor or sarcasm).

Only nurses at out-of-hours clinics and GP practices scored higher for safety climate than the HHN. Any explanation regarding the context, i.e., that treating more acutely ill or unstable patients requires more focus on patient safety is not supported, as European acute hospitals score lower than Norwegian HHN units (Table 3). Many initiatives have been carried out in recent years to improve patient safety levels in hospitals and recommendations for safety practices exist [48]. However, the climate still appears to be less safe here than the studies included in Table 3. The WHO campaign for patient safety points to organizational/ managerial topics together with team, individual, and work-environment topics as being essential to the success of this work [49]. There may be a need to search for reasons in the acute hospitals along these lines, as teamwork climate also seemed to score lower than in HHN units.

Healthcare providers with the longest employment duration at their current workplace had higher mean scores on both teamwork and safety climate. There are several possible explanations for this result. Being new to a site, even if having prior professional experience, may lead to a lower score for teamwork climate as individuals adapt to a new work environment. In contrast, having more experience probably leads to an individual having confidence in their own work and trust in their team, thus leading to a higher score for teamwork climate. Newer employees may also be more critical, seeing challenges with fresh eyes, which may increase patient safety awareness, thus leading to lower scores for both dimensions. Zhu et al. [50] found that nurses who lost confidence in safety and quality of care for their patients decided to leave their jobs to escape the physical and mental stress. Employees who do not leave, even when not satisfied with patient safety matters or working conditions, may be employees who are resigned to their role [50]. These employees may cause a climate for change to be lower than is necessary to improve safety and climate conditions.

\section{Strengths and limitations}

Due to the cross-sectional study design, our findings cannot support causal conclusions. Nonetheless, the study provides new information about patient safety culture in the largely unexplored area of HHN care. The low response rate limited the external validity of our findings. According to Sexton et al. [37], a response rate minimum of $60 \%$ is necessary to draw a firm conclusion when using the SAQ. However, it is recognized that achieving high response rates in survey research is increasingly challenging, and it is argued that response rate alone may not be 
sufficient evidence to judge study quality and/or validity [51]. A possible reason for the small sample could be that we did not exclude employees working less than full-time: employees working part-time could have lesser workplace commitment and thereby less interest in participating in the study. Another explanation may be that the survey was electronically distributed to individuals: Handing surveys directly to individuals could increase participation in the study [52]. There is a risk of selection bias, e.g., professionals with the most negative attitudes towards patient safety may have decided to not participate. Rogelberg et al. [53], however, determined that employees who are active non-responders (i.e., refuse to participate) have more negative attitudes to the organization than those who participate and that the passive non-responders (i.e., do not reply to the request) have attitudes similar to those who participate. They conclude that the risk of selection bias is smaller in attitude surveys. The fact that there were far more passive non-responders than active non-responders in our study thereby indicates that the findings would not be substantially different if the response rate was higher.

The SAQ has not, to our knowledge, been used thus far in the home health nursing care context. This study, therefore, provides important knowledge regarding the usefulness of the instrument. The fact that we used only two out of six factors in SAQ limit the comparability with studies using the full questionnaire. However, the dimensions teamwork and safety climate are considered to be the most important when investigating patient safety culture [37].

\section{Conclusion}

The HHN had higher scores for both safety climate and teamwork climate compared to the vast majority of other healthcare settings. Statistically significant differences were found for both dimensions. The results of our study indicate, however, that there is also room for improvement in the patient safety culture in Norwegian HHN. This study should be considered a preliminary report on the situation in this field, and further research on patient safety culture in HHN is needed. With a larger sample, it would be interesting to more closely investigate the variations we found in safety climate and teamwork climate related to background variables. Future research is also needed to investigate the associations between patient safety culture and the incidence of adverse events in HHN.

\section{Abbreviations}

ANOVA: Analysis of variance; GP: General practitioner; HHN: Home health nursing; SAQ: Safety Attitudes Questionnaire; SD: Standard deviation; SPSS: Statistical Package for the Social Sciences

\section{Acknowledgements}

The authors thank the HHN employees who contributed to the study by responding to the questionnaires. The project received funding from Nord University (former, Nord-Trøndelag University College, Faculty of Health and Science). The funders had no part in the study design; in the collection, analysis, and interpretation of data; and in the writing or publication of this manuscript.

Funding

The study did not receive any external funding.

Availability of data and materials

Please contact the author for data requests.

Authors' contributions

$\mathrm{RMO}$ and JB designed the study. RMO collected, analyzed, and interpreted the data. RMO created the tables and led the drafting of the manuscript. $\mathrm{RMO}$ and JB were both involved in critically revising the manuscript for important intellectual content and both read and approved the final manuscript.

\section{Ethics approval and consent to participate}

The project was approved by the Data protection Official for Research, Norwegian Social Sciences Data Service (NSD) (Ref. No. 2015/44114). Information on the aim of the study accompanied the questionnaires and completion of the questionnaire was considered informed consent for participation.

\section{Consent for publication}

Not applicable

\section{Competing interests}

The authors declare that they have no competing interests.

\section{Publisher's Note}

Springer Nature remains neutral with regard to jurisdictional claims in published maps and institutional affiliations.

\section{Author details \\ ${ }^{1}$ Centre for Care Research Mid-Norway, Nord University, Namsos, Norway. ${ }^{2}$ Faculty of Nursing and Health Science, Nord University, Levanger, Norway. ${ }^{3}$ Centre for Care Research/Faculty of Nursing and Health Science, PB 474, 7801 Namsos, Norway.}

Received: 3 October 2017 Accepted: 21 November 2017

Published online: 01 December 2017

References

1. Runciman W, Hibbert P, Thomson R, Van Der Schaaf T, Sherman H, Lewalle P. Towards an international classification for patient safety: key concepts and terms. Int J Qual Health Care. 2009;21:18-26.

2. Kohn LT, Corrigan JM, Donaldson MS. To err is human: building a safer health system. Washington: National Academies Press; 2000.

3. Vincent C. Patient safety. 2nd ed. Wiley: Chichester, UK; 2010

4. National Patient Safety Foundation (NPSF). Free from harm: accelerating patient safety improvement fifteen years after to err is human. 2015. http:// www.npsf.org/. Accesed 1 Mar 2017.

5. World Health Organization. Safer primary care: a global challenge. Summary of inaugural meeting. The Safer Primary Care Expert Working Group. 2013. http://www.who.int/patientsafety/summary_report_of_primary_care_ consultation.pdf. Accessed 1 Mar 2017.

6. Lorincz CY, Drazen E, Sokol PE, Neerukonda KV, Metzger J, Toepp MC, Maul L, Classen DC, Wynia MK. Research in ambulatory patient safety 2000-2010: a 10-year review. Chicago: American Medical Association; 2011. https://cymcdn.com/sites/ npsf.site-ym.com/resource/resmgr/PDF/Research-in-Amb-Pat-Saf_AMAr.pdf. Accesed 1 Mar 2017

7. Cresswell KM, Panesar SS, Salvilla SA, Carson-Stevens A, Larizgoitia I, Donaldson $L$, Bates D, Sheikh A. Global research priorities to better understand the burden of iatrogenic harm in primary care: an international delphi exercise. PLoS Med. 2013;10:11.

8. Vincent C, Amalberti R. Safer healthcare: Strategies for the real world. 1st ed: London: Springer Open; 2016. https://link.springer.com/content/pdf/10. 1007\%2F978-3-319-25559-0.pdf. Accessed 1 Mar 2017. 
9. van den Berg MJ, van Loenen T, Westert GP. Accessible and continuous primary care may help reduce rates of emergency department use. An international survey in 34 countries. Fam Pract. 2016;33:42-50.

10. Panesar SS, Desilva D, Carson-Stevens A, Cresswell KM, Salvilla SA, Slight SP, Javad S, Netuveli G, Larizgoitia I, Donaldson LJ, et al. How safe is primary care? A systematic review. BMJ Quality \& Safety. 2015:25:544-53.

11. Norsk Pasientskadeerstatning [The Norwegian System of Compensation to Patients). Mottatte saker - behandlingssted/type sak [Cases received - place of treatment/type of case]. http://www.npe.no/no/pasientsikkerhet-og-statistikk/ statistikk/mottatte-saker-behandlingssted-type-sak/. Accessed 1 Mar 2017.

12. Pasient- og brukerombudet [The Health \& Social Services ombudsmen]. Årsmelding 2015. Pasient- og brukerombudene i Norge. [Annual report 2016. The Health and Social Services Ombudsmen in Norway]. 2017. https:// helsenorge.no/SiteCollectionDocuments/pasient-\%20og\%20brukerombudet/ arsmelding-pobo-2015.pdf. Accessed 1 Mar 2017.

13. Helse- og omsorgsdepartementet [Ministry of Health and Care Services]. Pasientsikkerhetsprogrammet i trygge hender 24-7. Strategi 2014-2018. [The patient safety program In Safe Hands 24-7. Strategy 2014-2018], vol. 2012. Oslo: Helse- og omsorgsdepartementet.

14. Statistisk sentralbyrå [Statistics Norway]. Statistikkbanken: omsorgstjenester. Norway: care services. https://www.ssb.no/statistikkbanken/. Accessed 1 Mar 2017

15. Marengoni A, Angleman S, Melis R, Mangialasche F, Karp A, Garmen A, Meinow B, Fratiglioni L. Aging with multimorbidity: a systematic review of the literature. Ageing Res Rev. 2011;10:430-9.

16. Field TS, Gurwitz JH, Harrold LR, Rothschild J, Debellis KR, Seger AC, Auger JC, Garber LA, Cadoret C, Fish LS, et al. Risk factors for adverse drug events among older adults in the ambulatory setting. J Am Geriatr Soc. 2004;52:1349-54.

17. Gallagher PF, O'Connor MN, O'Mahony D. Prevention of potentially inappropriate prescribing for elderly patients: a randomized controlled trial using STOPP/START criteria. Clin Pharmacol Ther. 2011:89:845-54.

18. Scripcaru G, Mateus C, Nunes C. Adverse drug events-analysis of a decade. A Portuguese case-study, from 2004 to 2013 using hospital database. PLoS One. 2017;12:e0178626.

19. European Network for Patient Safety. (EUNetPaS). A general guide for education and training in patient safety. http://www.eu-patient.eu/globalassets/projects/ eunetpas/guidelines_final_22-06-2010.pdf. Accessed 1 Mar 2017.

20. Hessels AJ, Larson EL. Relationship between patient safety climate and standard precaution adherence: a systematic review of the literature. J Hosp Infect. 2016;92:349-62

21. Colla JB, Bracken AC, Kinney LM, Weeks WB. Measuring patient safety climate: a review of surveys. Qual Saf Health Care. 2005;14:364-6.

22. Mardon RE, Khanna K, Sorra J, Dyer N, Famolaro T. Exploring relationships between hospital patient safety culture and adverse events. J Patient Saf. 2010;6:226-32.

23. Hofmann DA, Mark B. An investigation of the relationship between safety climate and medication errors as well as other nurse and patient outcomes. Pers Psychol. 2006;59:847-69.

24. Thomas KS, Hyer K, Castle NG, Branch LG, Andel R, Weech-Maldonado R. Patient safety culture and the association with safe resident care in nursing homes. Gerontologist. 2012;52:802-11.

25. Hofoss D, Deilkas E. Roadmap for patient safety research: approaches and roadforks. Scand J Public Health. 2008;36:812-7.

26. Weaver SJ, Lubomksi LH, Wilson RF, Pfoh ER, Martinez KA, Dy SM. Promoting a culture of safety as a patient safety strategy: a systematic review. Ann Intern Med. 2013;158:369-74.

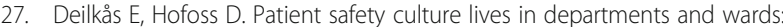
multilevel partitioning of variance in patient safety culture. BMC Health Serv Res. 2010;10:85.

28. Frankel A, Grillo SP, Pittman M, Thomas EJ, Horowitz L, Page M, Sexton B. Revealing and resolving patient safety defects: the impact of leadership WalkRounds on frontline caregiver assessments of patient safety. Health Serv Res. 2008;43:2050-66.

29. Singer JS, Gaba MD, Falwell MA, Lin MS, Hayes MJ, Baker ML. Patient safety climate in 92 US hospitals: differences by work area and discipline. Med Care. 2009:47:23-31.

30. Kristensen S, Christensen KB, Jaquet A, Møller Beck C, Sabroe S, Bartels P, Mainz J. Strengthening leadership as a catalyst for enhanced patient safety culture: a repeated cross-sectional experimental study. BMJ Open. 2016;6

31. Gallego B, Westbrook MT, Dunn AG, Braithwaite J. Investigating patient safety culture across a health system: multilevel modelling of differences associated with service types and staff demographics. Int J Qual Health Care. 2012;24:311-20.
32. Bondevik GT, Hofoss D, Husebo BS, Deilkas ECT. Patient safety culture in Norwegian nursing homes. BMC Health Serv Res. 2017:17:424.

33. Castle NG, Wagner LM, Perera S, Ferguson JC, Handler SM. Assessing resident safety culture in nursing homes: using the nursing home survey on resident safety. J Patient Saf. 2010;6:59-67.

34. Buljac-Samardzic M, van Wijngaarden JD, Dekker-van Doorn CM. Safety culture in long-term care: a cross-sectional analysis of the safety attitudes questionnaire in nursing and residential homes in the Netherlands. BMJ Quality \& Safety. 2015;25:424.

35. Halligan M, Zecevic A. Safety culture in healthcare: a review of concepts, dimensions, measures and progress. BMJ Quality \& Safety. 2011;20:338.

36. Kristensen S, Bartels P. Use of patient safety culture instruments and recommandations. Results of the EUNetPaS (European Society for Quality in Healthcare) project. 2010. http://www.seguridaddelpaciente.es/resources/ documentos/2016/eunetpas/WP1-REPORT\%20\%20Use\%20of\%20\%20PSCI\% 20and\%20recommandations\%20-\%20March\%20\%202010.pdf. Accessed 1 Mar 2017.

37. Sexton JB, Helmreich RL, Neilands TB, Rowan K, Vella K, Boyden J, Roberts PR, Thomas EJ. The Safety Attitudes Questionnaire: psychometric properties, benchmarking data, and emerging research. BMC Health Serv Res. 2006;6:44.

38. Deilkås E, Hofoss D. Psychometric properties of the Norwegian version of the Safety Attitudes Questionnaire (SAQ), Generic version (Short Form 2006). BMC Health Serv Res. 2008;8:191.

39. Bondevik GT, Hofoss D, Hansen EH, Deilks ECT. Patient safety culture in Norwegian primary care: a study in out-of-hours casualty clinics and GP practices. Scand J Prim Health Care. 2014;32:132-8.

40. Kristensen S, Hammer A, Bartels P, Sunol R, Groene O, Thompson CA, Arah OA, Kutaj-Wasikowska H, Michel P, Wagner C. Quality management and perceptions of teamwork and safety climate in European hospitals. Int J Qual Health Care. 2015;27:499-506.

41. Olsson C, Forsberg A, Bjerså K. Safety climate and readiness for implementation of evidence and person centered practice: a national study of registered nurses in general surgical care at Swedish university hospitals. BMC Nurs. 2016;15:54.

42. Tummers L, Groeneveld S, Lankhaar M. Why do nurses intend to leave their organization? A large scale analysis in long term care. J Adv Nurs. 2013;12: 2826-38.

43. Barrett A, Terry DR, Le Q, Hoang H. Factors influencing community nursing roles and health service provision in rural areas: a review of literature. Contemp Nurse. 2016;52:119-35.

44. Stuart EH, Jarvis A, Daniel K. A ward without walls? District nurses' perceptions of their workload management priorities and job satisfaction. J Clin Nurs. 2008;17:3012-20.

45. Terry D, Lê Q, Nguyen U, Hoang H. Workplace health and safety issues among community nurses: a study regarding the impact on providing care to rural consumers. BMJ Open. 2015:5

46. Katzenbach JR, Smith DK. The wisdom of teams : creating the highperformance organization. London: McGraw-Hill; 2005.

47. Jones A, Kelly D. Whistle-blowing and workplace culture in older peoples' care: qualitative insights from the healthcare and social care workforce. Sociol Health IIIn. 2014;36:986-1002

48. Shekelle PG, Wachter RM, Pronovost PJ, Schoelles K, McDonald KM, Dy SM, Shojania K, Reston J, Berger Z, Johnsen B, et al. Making health care safer II: an updated critical analysis of the evidence for patient safety practices. Evidence Report/Technology Assessment. 2013;211 https://www.ahrq.gov/. Accessed 1 Mar 2017

49. World Health Organization. Human factors in patient safety. Review of topics and tools. Report for methods and measures. Working Group of WHO Patent Safety/World Health Organization. 2009. http://www.who.int/ patientsafety/research/methods_measures/human_factors/human_factors_ review.pdf. Accessed 1 Mar 2017.

50. Zhu J, Rodgers S, Melia KM. The impact of safety and quality of health care on Chinese nursing career decision-making. J Nurs Manag. 2014;22:423-32.

51. Morton SMB, Bandara DK, Robinson EM, Carr PEA. In the 21st century, what is an acceptable response rate? Aust N Z J Public Health. 2012;36:106-8.

52. Allen S, Chiarella M, Homer CS. Lessons learned from measuring safety culture: an Australian case study. Midwifery. 2010;26:497-503.

53. Rogelberg SG, Conway JM, Sederburg ME, Spitzmüller C, Aziz S, Knight WE, Zedeck S. Profiling active and passive nonrespondents to an organizational survey. J Appl Psychol. 2003;88:1104-14. 